\title{
Assessment of diabetes self-management among diabetic patients attending Jeddah Care Center for Diabetes, Saudi Arabia.
}

Reem Alqahtani

King Abdul Aziz University Hospital

Sami Alzahrani

King Abdul Aziz University Hospital

Moneerah Alhemedi

King Abdul Aziz University Hospital

Asya Hawsa ( $\square$ asia_ameen@hotmail.com )

King Abdul Aziz University Hospital

Sarah Idris

King Abdul Aziz University Hospital

Shomokh Alotaibi

King Abdul Aziz University Hospital

\section{Research Article}

Keywords: Self-management, diabetes, glycemic control, Saudi Arabia

Posted Date: April 29th, 2021

DOI: https://doi.org/10.21203/rs.3.rs-469145/v1

License: (9) (i) This work is licensed under a Creative Commons Attribution 4.0 International License.

Read Full License 


\section{Assessment of diabetes self-management among 2 diabetic patients attending Jeddah Care Center for 3 Diabetes, Saudi Arabia 4}

Authors

Reem M, Alqahtani ${ }^{1}$ MBвS,SBFM, Sami H, Alzahrani ${ }^{1}$ MBBS,SBFM,ABFM, Asya A, Hawsa ${ }^{2}$ MBBS, 7 Sarah M, Idris ${ }^{2}{ }_{\text {MBBS }}$, Shomokh F, Alotaibi ${ }^{2}{ }_{\text {MBBS }}$, Moneerah A, Alhemedi ${ }^{3},{ }_{\text {MBBS,SBFM. }} 8$

${ }^{1}$ Assistant professor consultant, Department of Family Medicine, King Abdul-Aziz 9 University, Jeddah, Saudi Arabia.. $\quad 10$

${ }^{2}$ Faculty of Medicine, King Abdul-Aziz University, Jeddah, Saudi Arabia. $\quad 11$

${ }^{3}$ Family Medicine Specialist, Department of Family Medicine, King Abdulaziz, 12 Hospital, Jeddah, Saudi Arabia 13

Email addresses:

rmalqahtani@kau.edu.sa, drsamihz@gmail.com, asia ameen@hotmail.com,

Corresponding Author:

Asya Ameen Hawsa MBвS.

Faculty of Medicine, King Abdul-Aziz University,

Jeddah 22252 3646, Saudi Arabia.

Asia_ameen@hotmail.com

$+00966543602825$

ORCID: https://orcid.org/0000-0002-0240-5576 


\section{Abstract}

Objectives:

To assess the levels and the associated demographic factors with diabetic self-

management (DSM) among diabetic patients in Saudi Arabia. The impact of implementing DSM practices on glycemic control was additionally investigated.

Results:

The responses of 349 patients were analyzed (51.0\% males and $37.2 \%$ obese). The

median (IQR) raw DSMS score was 187 (165-205). Higher DSMS scores were reported

for young adults (aged 20-29 years), insulin users, employed patients, as well as those

with normal body mass index values and normal HbA1c results compared to their

counterparts. Low HbA1c values were linearly associated with high scores of the

healthy eating $(\beta=-0.014, \mathrm{p}=0.018)$ and physical activity subscales $(\beta=90-0.009$,

$\mathrm{p}=0.042)$.

Keywords: Self-management; diabetes; glycemic control; Saudi Arabia 


\section{Introduction}

Diabetes is a chronic condition that has detrimental consequences on the well-being of affected patients, their families, societies, and healthcare settings(1). Estimates indicate that the global prevalence of diabetes was $9.3 \%$ in 2019, and the figure is projected to reach as high as $10.2 \%$ by 2030(2). In Saudi Arabia, data related to diabetes is relatively scarce, and few nation-wide epidemiological studies have been conducted. Based on available evidence, the prevalence of T2DM has linearly increased from $18.2 \%$ in 2005 to $31.6 \%$ in $2011(3,4)$, and the country-based prevalence is on the rise. As with other countries, diabetes in Saudi Arabia is linked to the growing burden of obesity(5).

In general, premature mortality attributable to diabetes is associated with the incidence of preventable diabetes-related complications. These include macrovascular and microvascular complications(6). The development of such complications could be delayed or prevented via improving glycemic control and adhering to tailored managemental plans. Therefore, multidisciplinary approach including selfmanagement has been cited as a strong determinant of improved health outcomes, better glycemic control and reduced healthcare costs(7-9). As such, diabetes self-management (DSM), defined as the actual performance of self-care activities, plays an integral role in the success of diabetes control and alleviating the impact of disease-related complications.

However, DSM is a complex, multifaceted process, in which the patient would be responsible for caring for his condition via distinct skills, confidence, knowledge, and commitment. Each patient has a unique lifestyle, and self-management practices might aimed to assess the level of DSM practice of patients with diabetes in Saudi Arabia. Additionally, we explored the differences in DSM levels across demographic groups of 


\section{Main text}

A paper based-survey cross-sectional study was carried out during the period between 72 June 2019-2020 at Jeddah Care Center for Diabetes, King Abdul-Aziz Hospital (KAH). Diabetic patients with T1DM and T2DM, who had been receiving treatment for at least 6 months before participation were eligible. Males and females aged between 20 and 79 years were included. Excluded population: Gestational DM, those with major complications that might have hindered their self-management activities, and those with cognitive impairment or psychiatric illnesses.

The sample size was calculated using the OpenEpi online calculator(11). Considering a $95 \%$ confidence interval (CI) the required sample size is 384.450 diabetic patients were targeted, A convenience sample of 349 patients agreed to participate in the study, and a written consent was taken.

A semi-structured validated questionnaire developed by Sousa et al(12), consisted of three major domains: 1) demographic characteristics, 2) diabetes-related data and 3) the Diabetes Self-Management Scale (DSMS), which measures the level of DSM. The DSMS comprises of Likert-type 60-item distributed across seven components, including dietary control, physical activity, monitoring blood glucose, taking medication, foot care, problem-solving, and risk reduction. The reliability of the overall DSMS scale was graded as "excellent" (Table S1). The responses to each item were graded as follow: $1=$ never, $2=$ rarely, $3=$ sometimes, and $4=$ frequently. Therefore, the total score for each participant ranged between 60 and 240, where high scores have indicated high DSM levels. DSMS's Arabic version has been tested and validated on an Arab population(13).

Data was collected by the researchers in the center; for each participant, HbA1c level 94 that had been measured in the past 3 months were obtained from the medical records. Body weight and height were measured according to standard procedure, missing 95 values of body weight and height were due to participants rejection. Different Body Mass Index (BMI) categories were defined according to the World Health Organization's criteria(14). Adequate glycemic control was classified as good $(\mathrm{HbA} 1 \mathrm{c} \leq 7 \%)$ or poor $(\mathrm{HbA} 1 \mathrm{c}>7 \%)(15,16)$.

Numerical variables were presented as means and standard deviations, whereas categorical variables were expressed as frequencies and percentages. Missing-data body weight, indicating that these data were missing completely at random. Accordingly, the linear interpolation method was used to impute the missing data. The reliability of the questionnaire was assessed using Cronbach's alpha values. Non- 
parametric tests were used based on the results of tests of normality on the scores of the

DSMS scale and subscales (Kolmogorov-Smirnov and Shapiro-Wilk tests [P-value $<0.0001$ for the DSMS scale and all subscales]). Quantitative scores were expressed as medians and interquartile ranges (IQRs). The scores of different demographic groups were compared using the Mann-Whitney U-test and Kruskal-Wallis $\mathrm{H}$ test, where applicable. The impact of DSM practice on glycemic control was assessed by analyzing the effects of DSMS scores (for the main scale and subscales) as predictor variables on $\mathrm{HbA1c}$ quantitative values (dependent variable) in a linear regression model. Statistical analysis was performed using the IBM SPSS version 26.0.

\section{Results}

349 patients agreed to participate in the study, response rate (77.5\%). Missing data were imputed in $50(14.3 \%)$ patients for height and 47 (13.5\%) for body weight, and the BMI was calculated for patients with imputed data. Approximately half of the respondents were males (51.0\%) and unemployed (53.3\%). Majority of patients were married (71.6\%) and overweight or obese (38.4\% and 37.2\%, respectively) Table 1.

Majority of patients had been diagnosed with T2DM (73.1\%), and less than half of them had the disease for 6-10 years $(40.4 \%)$. In general, 50 complications had occurred in 40 patients (11.5\%), Table 1. Abnormal vision was the most frequently reported complication (34.0\%), followed by hypoglycemic attacks (16.0\%) and retinal hemorrhage (14.0\%) (Figure S1). The mean value of HbA1C was $8.08 \% \pm 1.69$, and $47.9 \%$ of patients had poor glycemic control (Table 1).

Considering the analysis of two categorical variables, employed diabetic patients scored higher than unemployed patients regarding their self-management practices (median [IQR] values were 80.00 [71.25-86.67] versus 74.58 [66.25-83.33], respectively, $\mathrm{P}=$ Wallis $\mathrm{H}$ test revealed significant differences in the total DSMS scores across subgroups of age $(\mathrm{P}<0.0001)$, treatment type $(\mathrm{P}<0.0001)$, $\mathrm{BMI}(\mathrm{P}=0.001)$, and marital status $(\mathrm{P}=$ 0.026). Pairwise comparisons were carried out to further investigate the sources of differences (Table S2). Using a Bonferroni correction for multiple tests, the findings indicated consistently higher median (IQR) scores of diabetes self-management among values than obese patients $(\mathrm{P}=0.001)$, and patients receiving insulin only than those who had received oral and insulin therapies and exclusive oral therapies $(\mathrm{P}=0.001$ for both comparisons). Besides, patients aged 20-29 years had higher scores than all other age groups ( $\mathrm{P} \leq 0.001$ for all comparisons). Regarding the analysis of DSMS subscales, 
for the dietary control subscale (80.0 [72.5-89.27] versus 75.0 [68.3-83.3] for good and

\section{Discussion}

Healthy lifestyle practices are an important determinant of management outcomes in timepoints, can be an integral part of the management plan for those who cannot reach the recommended therapeutic goal. In this study, the raw score of the DSMS scale was 187 for the total population, and higher scores were evident in distinct demographic groups, including single and employed participants, young adults (20-29 years), along with those who are receiving insulin therapy, as compared to their counterparts.

The reported DSMS score in the current study is higher than the mean score reported in previous cross-sectional study among patients attending primary healthcare centers in Jeddah(17). However, we demonstrated a relatively high level of poor glycemic control (48\%) among patients with T1DM and T2DM. Similarly, recent studies carried out in Riyadh and Al Kharj showed that $43.13 \%$ and $44.5 \%$ of patients had uncontrolled diabetes, respectively $(18,19)$. Other national studies have shown alarming levels in T2DM, where suboptimal HbA1c values were reported among $74.0 \%$ of patients in Jizan(20) and $73.8 \%$ in Al-Madinah(21). Such findings underline the need to find urgent solutions to improve glycemic control via effective self-managemental strategies.

The outcomes indicate an association between protective self-management strategies and improved glycemia. More specifically, a negative linear correlation was found between the scores of healthy eating and physical activity and HbA1c levels, indicating an optimal glycemic control in patients with good adherence to these recommendations. 
Young adults expressed higher compliance levels to self-management practices than 185 other age groups. Supporting diabetic young adults is necessary since they are more likely to develop diabetes-related cardiovascular complications than their counterparts 187 without diabetes(24). Their high DSM scores are possibly because of their increased knowledge regarding the importance of maintaining a healthy lifestyle. Knowledge levels might have played significant roles in promoting DSM practices among employed participants, which was corroborated in a recent study conducted in Riyadh city(25). Employment has been also associated with improved insulin use $(26,27)$, and this have caused a significant interaction to increase DSM scores among insulin users in our study. Finally, it was not surprising that obese patients had lower DSM scores than those with normal BMI values since the formers are more likely to be noncompliant to healthy lifestyle approaches. Importantly, demographic groups with low DSM scores, including unemployed patients, middle-aged and older adults, obese patients, and non-insulin users should be targeted in future health campaigns to promote their knowledge levels and improve their compliance to DSM practices, considering the established cultural and societal barriers.

Based on the findings, self-management in diabetes is a crucial aspect of patient management. A multidisciplinary approach should therefore entail patient-centered

In conclusion, the levels of DSM were adequate as reported by the diabetic patients in

\section{Limitations:}

This study utilized the DSMS, which showed good to excellent reliability indices. 
List of Abbreviations

DM: Diabetes Mellitus

226

HbA1c: Glycated Hemoglobin

227

T1DM: Type 1 Diabetes Mellitus

228

T2DM: Type 2 Diabetes Mellitus

229

DSM: Diabetic Self-Management

230

DSMS: Diabetic Self-Management Scale

IQR: Interquartile range

BMI: Body Mass Index

233

KAUH: King Abdul-Aziz University Hospital

KAH: King Abdul-Aziz Hospital 


\section{Declarations:}

All eligible participants were informed about the objectives of the study, and the 240 confidentiality of the data were assured to ensure privacy. Patients' data was exclusively utilized for research purposes. The study was carried out following applicable regulations of the King Abdul-Aziz University Hospital (KAUH), and ethical approval was obtained from the institutional review board (125-19). (HA-02-J008) \#No of Registration At National Committee of Bio. \& Med. Ethics.

A written consent was taken from each participant after obtaining the ethical approval,

- Consent for publication

Not applicable

- Availability of data and materials

The data that support the findings of this study are available from Jeddah Care Center for Diabetes, King Abdul-Aziz Hospital. But restrictions apply to the availability of these data, which were used under license for the current study, and so are not publicly available. Data are however available from the authors upon reasonable request and 253 with permission of Jeddah Care Center for Diabetes, King Abdul-Aziz Hospital.

RA and SA designed and directed the study; AH, SI, SHA and MA contributed to data 
The authors appreciate the Jeddah Care Center for Diabetes administration in 269 facilitating the data acquisition process. 


\section{References}

1. Williams R, Karuranga S, Malanda B, Saeedi P, Basit A, Besançon S, et al. 274 Global and regional estimates and projections of diabetes-related health expenditure: 275 Results from the International Diabetes Federation Diabetes Atlas, 9th edition. Diabetes 276 Research and Clinical Practice. 2020;162:108072. 277

2. Saeedi P, Petersohn I, Salpea P, Malanda B, Karuranga S, Unwin N, et al. 278 Global and regional diabetes prevalence estimates for 2019 and projections for 2030279 and 2045: Results from the International Diabetes Federation Diabetes Atlas, 9th 280 edition. Diabetes research and clinical practice. 2019;157:107843. 281 3. Alqurashi KA, Aljabri KS, Bokhari SA. Prevalence of diabetes mellitus in a 282 Saudi community. Annals of Saudi medicine. 2011;31(1):19-23. 283

4. Alotaibi A, Perry L, Gholizadeh L, Al-Ganmi A. Incidence and prevalence rates 284 of diabetes mellitus in Saudi Arabia: An overview. Journal of Epidemiology and Global 285 Health. 2017;7(4):211-8. 286 5. Alhazmi RS, Ahmed AAB, Alshalan MH, Alfuhigi ZD, Alhazmi SF, Aldughmi 287 AN, et al. Prevalence of diabetes mellitus and its relation with obesity in Turaif (Saudi 288 Arabia) in 2017. Electronic physician. 2017;9(10):5531. 289

6. Harding JL, Pavkov ME, Magliano DJ, Shaw JE, Gregg EW. Global trends in 290 diabetes complications: a review of current evidence. Diabetologia. 2019;62(1):3-16. 291

7. Chrvala CA, Sherr D, Lipman RD. Diabetes self-management education for 292 adults with type 2 diabetes mellitus: A systematic review of the effect on glycemic 293 control. Patient education and counseling. 2016;99(6):926-43. 294

8. Powers MA, Bardsley J, Cypress M, Duker P, Funnell MM, Fischl AH, et al. 295 Diabetes Self-management Education and Support in Type 2 Diabetes: A Joint Position 296 Statement of the American Diabetes Association, the American Association of Diabetes 297 Educators, and the Academy of Nutrition and Dietetics. Clinical diabetes : a publication 298 of the American Diabetes Association. 2016;34(2):70-80. 299

9. Zheng F, Liu S, Liu Y, Deng LJJodr. Effects of an outpatient diabetes self- 300 management education on patients with type 2 diabetes in China: a randomized 301 controlled trial. Journal of diabetes research.2019. 
10. Al-Khaledi M, Al-Dousari H, Al-Dhufairi S, Al-Mousawi T, Al-Azemi R, Al- 303 Azimi F, et al. Diabetes self-management: a key to better health-related quality of life 304 in patients with diabetes. Medical Principles and Practice. 2018;27(4):323-31. 305

11. Dean A, Sullivan KM, Soe MM. OpenEpi: open source epidemiologic statistics 306 for public health, version 2013 [Available from: https://www.openepi.com/. 307

12. Sousa VD, Hartman SW, Miller EH, Carroll MA. New measures of diabetes 308 self-care agency, diabetes self-efficacy, and diabetes self-management for insulin- 309 treated individuals with type 2 diabetes. Journal of Clinical Nursing. 2009;18(9):1305- 310 12.

13. Alrahbi H. Diabetes Self-management (DSM) in Omani with Type-2 diabetes. 312 International Journal of Nursing Sciences. 2014;1(4):352-9. 313

14. World Health Organization. Obesity and overweight Geneva: WHO; 2017314 [Available from: https://www.who.int/news-room/fact-sheets/detail/obesity-and- 315

$\begin{array}{ll}\text { overweight. } & 316\end{array}$

15. Aschner P. New IDF clinical practice recommendations for managing type 2317 diabetes in primary care. Diabetes Res Clin Pract. 2017;132:169-70. 318

16. American Diabetes Association. 2. Classification and Diagnosis of Diabetes: 319

Standards of Medical Care in Diabetes-2018. Diabetes care. 2018;41(Suppl 1):S13-s27. 320

17. Bakhsh E, Alqutub S. LEVELS AND BARRIERS OF GLYCEMIC CONTROL 321 AND SELF-MANAGEMENT AMONG DIABETIC PATIENTS IN PRIMARY 322 HEALTH CARE IN JEDDAH: A CROSS-SECTIONAL STUDY. International 323 Journal of Advanced Research. 2017;5:1721-33. 324

18. Almetwazi M, Alwhaibi M, Balkhi B, Almohaini H, Alturki H, Alhawassi T, et 325

al. Factors associated with glycemic control in type 2 diabetic patients in Saudi Arabia. 326 Saudi Pharmaceutical Journal. 2019;27(3):384-8. 327

19. Al Dossari KK, Ahmad G, Aljowair A, Alqahtani N, Shibrayn MB, Alshathri 328

M, et al. Association of vitamin d with glycemic control in Saudi patients with type 2329 diabetes: A retrospective chart review study in an emerging university hospital. Journal 330 of Clinical Laboratory Analysis. 2020;34(2):e23048. 331

20. Badedi M, Solan Y, Darraj H, Sabai A, Mahfouz M, Alamodi S, et al. Factors 332 Associated with Long-Term Control of Type 2 Diabetes Mellitus. J Diabetes Res. 333 2016;2016:2109542. 334 
21. Abou-Gamel M, Al-Moghamsi Ea, Jabri G, Alsharif A, Al-Rehaili R, Al- 335

Gabban A, et al. Level of Glycemic Control and Barriers of Good Compliance among 336

Diabetic Patients in Al-Madina, Kingdom of Saudi Arabia. British Journal of Medicine 337

and Medical Research. 2015;5:819-30. 338

22. American Diabetes Association. 5. Lifestyle Management: Standards of 339 Medical Care in Diabetes-2019. Diabetes care. 2019;42(Suppl 1):S46-s60. 340

23. Al-Hazzaa HM. Physical inactivity in Saudi Arabia revisited: A systematic 341

review of inactivity prevalence and perceived barriers to active living. Int J Health Sci 342

(Qassim). 2018;12(6):50-64. 343

24. Hillier TA, Pedula KL. Complications in young adults with early-onset type 2344

diabetes: losing the relative protection of youth. Diabetes care. 2003;26(11):2999-3005. 345

25. Abouammoh NA, Alshamrani MA. Knowledge about Diabetes and Glycemic 346

Control among Diabetic Patients in Saudi Arabia. Journal of diabetes research. 347

2020;2020:1239735-. 348

26. Mufunda E, Ernersson Å, Hjelm K. Limited knowledge of diabetes in patients 349

attending an outpatient diabetes clinic at a referral hospital in Zimbabwe: a cross- 350

sectional study. Pan Afr Med J. 2018;29:144-. 351

27. Jasper US, Opara MC, Pyiki EB, Akinrolie O. Knowledge of insulin use and its 352

determinants among Nigerian insulin requiring diabetes patients. J Diabetes Metab 353

Disord. 2014;13(1):10-.

28. He X, Li J, Wang B, Yao Q, Li L, Song R, et al. Diabetes self-management 355

education reduces risk of all-cause mortality in type 2 diabetes patients: a systematic 356

review and meta-analysis. Endocrine. 2017;55(3):712-31. 357

29. Beck J, Greenwood DA, Blanton L, Bollinger ST, Butcher MK, Condon JE, et 358

al. 2017 National standards for diabetes self-management education and support. The 359

Diabetes Educator. 2018;44(1):35-50. 360 
Table 1: Demographic and clinical characteristics of the responding patients $(n=349)$.

\begin{tabular}{|c|c|c|c|}
\hline Parameter & Category & Frequency & Percentage \\
\hline \multirow[t]{2}{*}{ Gender } & Male & 178 & 51.00 \\
\hline & Female & 171 & 49.00 \\
\hline \multirow[t]{6}{*}{ Age } & $20-29$ & 51 & 14.60 \\
\hline & $30-39$ & 49 & 14.00 \\
\hline & $40-49$ & 62 & 17.80 \\
\hline & $50-59$ & 81 & 23.20 \\
\hline & $60-69$ & 74 & 21.20 \\
\hline & $70-79$ & 32 & 9.20 \\
\hline \multirow[t]{4}{*}{ Marital Status } & Single & 60 & 17.20 \\
\hline & Married & 250 & 71.60 \\
\hline & Divorced & 14 & 4.00 \\
\hline & Widow & 25 & 7.20 \\
\hline \multirow[t]{6}{*}{ Educational Level } & Illiterate & 61 & 17.50 \\
\hline & Primary & 40 & 11.50 \\
\hline & Preparatory & 38 & 10.90 \\
\hline & Secondary & 109 & 31.20 \\
\hline & University & 84 & 24.10 \\
\hline & Diploma & 17 & 4.90 \\
\hline \multirow{2}{*}{ Occupational Status } & Employed & 163 & 46.70 \\
\hline & Unemployed & 186 & 53.30 \\
\hline \multirow[t]{4}{*}{ Income (per month) } & $\leq 3,000 \mathrm{SAR}$ & 145 & 41.50 \\
\hline & 3,000-5,000 SAR & 120 & 34.40 \\
\hline & $5,000-10,000$ SAR & 53 & 15.20 \\
\hline & $\geq 10,000 \mathrm{SAR}$ & 31 & 8.90 \\
\hline height $(\mathrm{cm})$ & Mean \pm SD & 161.78 & 10.40 \\
\hline Body Weight (kg) & Mean \pm SD & 77.03 & 20.40 \\
\hline BMI & Mean \pm SD & 29.47 & 8.00 \\
\hline \multirow[t]{6}{*}{ BMI category } & Underweight & 7 & 2.00 \\
\hline & Normal & 78 & 22.30 \\
\hline & Overweight & 134 & 38.40 \\
\hline & Class 1 Obesity & 82 & 23.50 \\
\hline & Class 2 Obesity & 22 & 6.30 \\
\hline & Class 3 Obesity & 26 & 7.40 \\
\hline \multirow[t]{2}{*}{ Type of diabetes } & Type 1 & 94 & 26.90 \\
\hline & Type 2 & 255 & 73.10 \\
\hline \multirow[t]{4}{*}{ Duration of diabetes } & $\leq 5$ years & 87 & 24.90 \\
\hline & $6-10$ years & 141 & 40.40 \\
\hline & 11-20 years & 89 & 25.50 \\
\hline & $\geq 21$ years & 32 & 9.20 \\
\hline
\end{tabular}




\begin{tabular}{llll}
\hline Treatment Type & Oral only & 180 & 51.60 \\
& Oral and insulin & 67 & 19.20 \\
& Insulin only & 100 & 28.70 \\
& No treatment & 2 & 0.60 \\
\hline Complications existence & No & 309 & 88.50 \\
& Yes & 40 & 11.50 \\
\hline HbA1c $(\%)$ & Mean \pm SD & 8.08 & 1.69 \\
\hline Glycemic control & Good (HbA1c $\leq 7 \%)$ & 125 & 35.8 \\
& Poor (HbA1c $>7 \%)$ & 224 & 64.2 \\
\hline
\end{tabular}


Table 2: The relationship between DSMS scores and demographic characteristics

\begin{tabular}{|c|c|c|c|}
\hline \multirow[t]{2}{*}{ Parameter } & \multirow[t]{2}{*}{ Category } & \multicolumn{2}{|l|}{ DSMS score } \\
\hline & & Median (IQR) & $\mathbf{P}$ \\
\hline Gender & $\begin{array}{l}\text { Male } \\
\text { Female }\end{array}$ & $\begin{array}{l}78.96(69.58-85.10) \\
76.25(66.67-85.42)\end{array}$ & $0.366^{\mathrm{M}}$ \\
\hline Age & $\begin{array}{l}20-29 \\
30-39 \\
40-49 \\
50-59 \\
60-69 \\
70-79\end{array}$ & $\begin{array}{l}86.25(76.25-91.25) \\
76.67(65.21-87.08) \\
76.04(61.98-82.50) \\
76.67(64.79-83.33) \\
75.83(70.83-84.17) \\
77.71(66.35-83.96)\end{array}$ & $<0.0001 * \mathrm{k}$ \\
\hline BMI & $\begin{array}{l}\text { Underweight } \\
\text { Normal } \\
\text { Overweight } \\
\text { Obese }\end{array}$ & $\begin{array}{l}81.25(72.92-87.92) \\
83.13(73.23-88.44) \\
77.29(68.13-86.25) \\
75.21(65.31-82.08)\end{array}$ & $0.001 * \mathrm{k}$ \\
\hline Marital status & $\begin{array}{l}\text { Married } \\
\text { Single } \\
\text { Divorced } \\
\text { Widow }\end{array}$ & $\begin{array}{l}77.71(68.65-83.85) \\
83.13(72.92-90.00) \\
78.13(64.38-86.77) \\
71.25(65.42-82.50)\end{array}$ & $0.026^{* \mathrm{k}}$ \\
\hline $\begin{array}{l}\text { Educational } \\
\text { level }\end{array}$ & $\begin{array}{l}\text { Illiterate } \\
\text { Primary } \\
\text { Preparatory } \\
\text { Secondary } \\
\text { University } \\
\text { Diploma }\end{array}$ & $\begin{array}{l}74.58(66.25-83.33) \\
72.08(62.19-83.96) \\
76.04(65.73-81.46) \\
79.58(71.25-86.04) \\
79.58(68.02-89.48) \\
79.58(72.92-84.79)\end{array}$ & $0.080^{\mathrm{k}}$ \\
\hline $\begin{array}{l}\text { Occupational } \\
\text { Status }\end{array}$ & $\begin{array}{l}\text { Employed } \\
\text { Unemployed }\end{array}$ & $\begin{array}{l}80.00(71.25-86.67) \\
74.58(66.25-83.33)\end{array}$ & $0.003 * \mathrm{M}$ \\
\hline Monthly salary & $\begin{array}{l}\leq 3,000 \mathrm{SAR} \\
3,000-5,000 \mathrm{SAR} \\
5,000-10,000 \mathrm{SAR} \\
\geq 10,000 \mathrm{SAR}\end{array}$ & $\begin{array}{l}78.33(67.50-85.00) \\
78.96(69.69-85.42) \\
78.75(70.63-86.88) \\
72.50(55.42-77.08)\end{array}$ & $0.059^{\mathrm{k}}$ \\
\hline $\begin{array}{l}\text { Duration of } \\
\text { diabetes }\end{array}$ & $\begin{array}{l}\leq 5 \text { years } \\
6-10 \text { years } \\
11-20 \text { years } \\
\geq 21 \text { years }\end{array}$ & $\begin{array}{l}76.25(69.17-86.67) \\
78.75(69.58-85.21) \\
78.75(64.58-84.38) \\
74.17(67.50-84.17)\end{array}$ & $0.645^{\mathrm{k}}$ \\
\hline Treatment type & $\begin{array}{l}\text { Tablets only } \\
\text { Tablets and insulin } \\
\text { Insulin only } \\
\text { No treatment }\end{array}$ & $\begin{array}{l}77.29(67.60-83.33) \\
73.75(65.42-83.33) \\
83.13(72.92-90.42) \\
72.50(70.00-75.00)\end{array}$ & $<0.0001 * \mathrm{k}$ \\
\hline
\end{tabular}

IQR: interquartile range; $K$ : the difference between groups was tested using Kruskal-Wallis $H$ test; M: the difference between groups was tested using Mann-Whitney U Test (two-tailed test); * significant difference at $P<0.05$ 
Table 3: The relationship between DSMS scores and glycemic control (poor and good levels of HbA1c control) and the impact of selfmanagement scores (as predictor variables) on quantitative HbA1c results.

\begin{tabular}{|c|c|c|c|c|c|c|c|}
\hline \multirow[t]{2}{*}{ Parameter } & \multicolumn{3}{|l|}{ Glycemic control } & \multicolumn{2}{|l|}{ Univariate LRA } & \multicolumn{2}{|l|}{ Multivariate LRA } \\
\hline & Good & Poor & $\mathbf{P}^{\mathrm{M}}$ & $\beta(95 \%$ CI) & $\mathbf{P}$ & $\beta(95 \%$ CI) & $\mathbf{P}$ \\
\hline Dietary Control & $80(72.5-89.17)$ & $75(68.33-83.33)$ & $0.002 *$ & $-0.017(-0.028,-0.005)$ & $0.005 *$ & $-0.014(-0.025,-0.002)$ & $0.018 *$ \\
\hline Physical Activity & $75(54.17-87.5)$ & $70.83(50-79.17)$ & $0.014 *$ & $-0.013(-0.021,-0.005)$ & $0.001 *$ & $-0.009(-0.017,0.0001)$ & $0.042 *$ \\
\hline $\begin{array}{l}\text { Monitoring Blood } \\
\text { Glucose }\end{array}$ & $75(55-85)$ & $75(55-80)$ & 0.41 & $-0.008(-0.016,0.001)$ & 0.073 & NA & NA \\
\hline Taking Medication & $70.83(25-100)$ & 75 (38.54-95.83) & 0.313 & $0.004(-0.002,0.01)$ & 0.209 & NA & NA \\
\hline Foot Care & $85.71(75-100)$ & $78.57(72.32-92.86)$ & 0.065 & $-0.007(-0.015,0.001)$ & 0.088 & NA & NA \\
\hline Problem Solving & $87.5(81.25-90.63)$ & $84.38(75-90.63)$ & 0.058 & $-0.008(-0.02,0.005)$ & 0.23 & NA & NA \\
\hline Risk Reduction & $86.54(75-94.23)$ & $82.69(69.23-92.31)$ & 0.251 & $-0.004(-0.013,0.005)$ & 0.411 & NA & NA \\
\hline Overall & $80.83(69.58-87.29)$ & 76.67 (67.5-83.65) & $0.038 *$ & $-0.012(-0.024,0.001)$ & 0.06 & NA & NA \\
\hline
\end{tabular}

M: the difference between groups was tested using Mann-Whitney U Test (two-tailed test); * significant values at P<0.05; LRA: linear regression analysis; NA: not applicable 


\section{Supplementary Files}

This is a list of supplementary files associated with this preprint. Click to download.

- tablesDMcopy.pdf

- Supplementary.pdf 